Corrigendum

\title{
Corrigendum to "Local Relationship between Global-Flash Multifocal Electroretinogram Optic Nerve Head Components and Visual Field Defects in Patients with Glaucoma"
}

\author{
Chan Hee Moon, Jungwoo Han, Young-Hoon Ohn, and Tae Kwann Park \\ Department of Ophthalmology, Soonchunhyang University College of Medicine, Bucheon Hospital, Bucheon 14584, Republic of Korea \\ Correspondence should be addressed to Tae Kwann Park; tkpark@schmc.ac.kr \\ Received 18 January 2016; Accepted 27 March 2016 \\ Copyright (C) 2016 Chan Hee Moon et al. This is an open access article distributed under the Creative Commons Attribution \\ License, which permits unrestricted use, distribution, and reproduction in any medium, provided the original work is properly \\ cited.
}

In the article titled "Local Relationship between Global-Flash Multifocal Electroretinogram Optic Nerve Head Components and Visual Field Defects in Patients with Glaucoma" [1] the affiliation of the first author was incorrectly listed as "Department of Ophthalmology, Seoul St. Mary's Hospital, The Catholic University of Korea College of Medicine, Seoul 06591, Republic of Korea." The correct affiliations are presented above.

\section{References}

[1] C. H. Moon, J. Han, Y. Ohn, and T. K. Park, "Local relationship between global-flash multifocal electroretinogram optic nerve head components and visual field defects in patients with glaucoma," Journal of Ophthalmology, vol. 2015, Article ID 397495, 8 pages, 2015. 


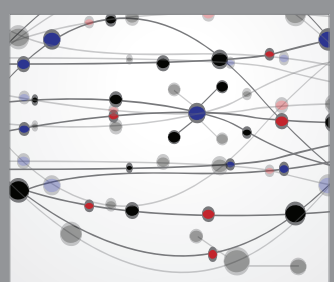

The Scientific World Journal
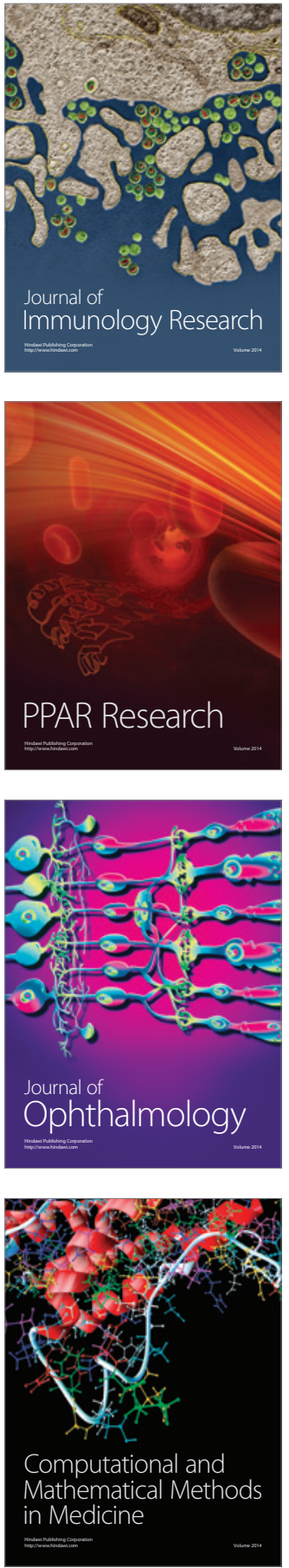

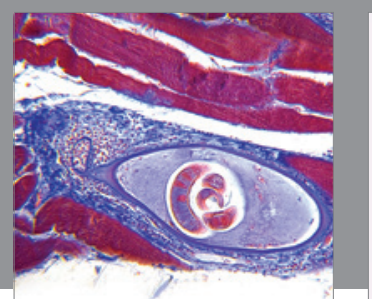

Gastroenterology Research and Practice

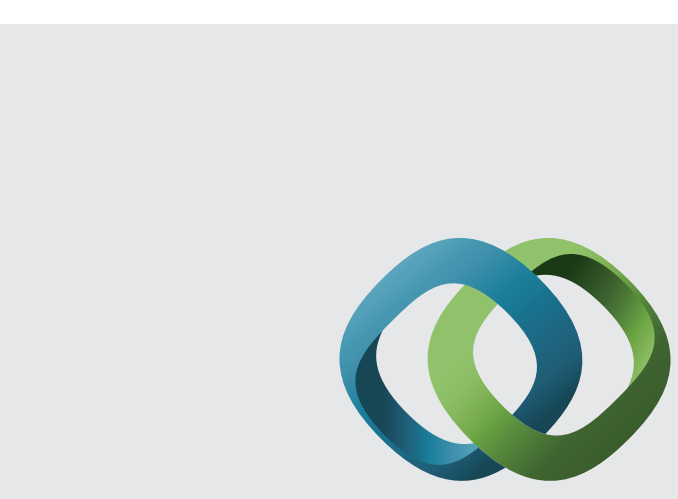

\section{Hindawi}

Submit your manuscripts at

http://www.hindawi.com
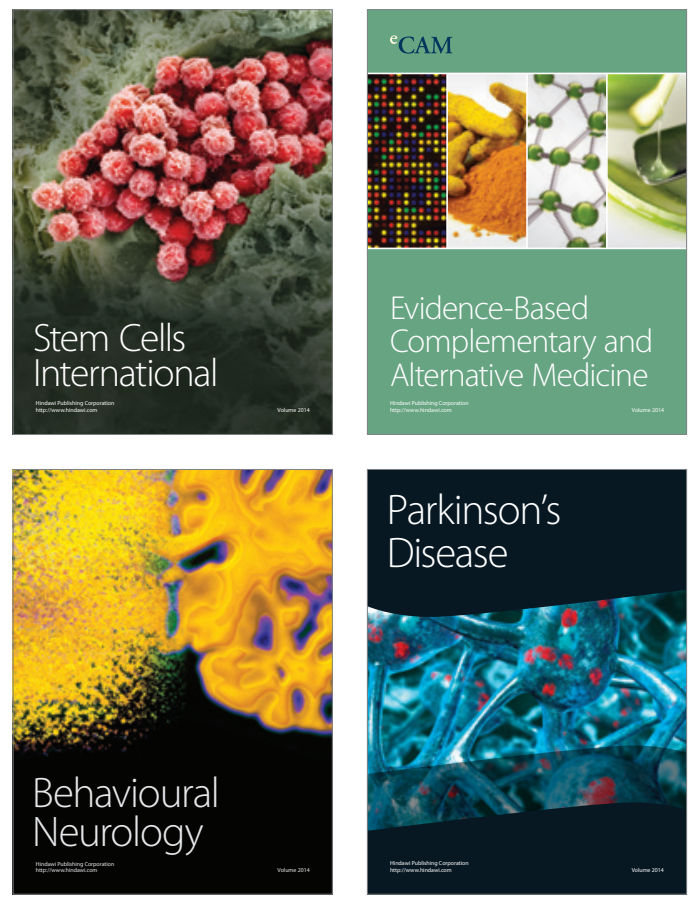
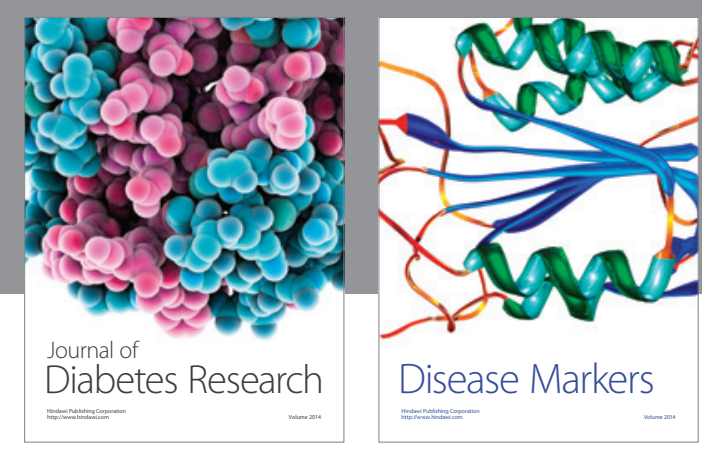

Disease Markers
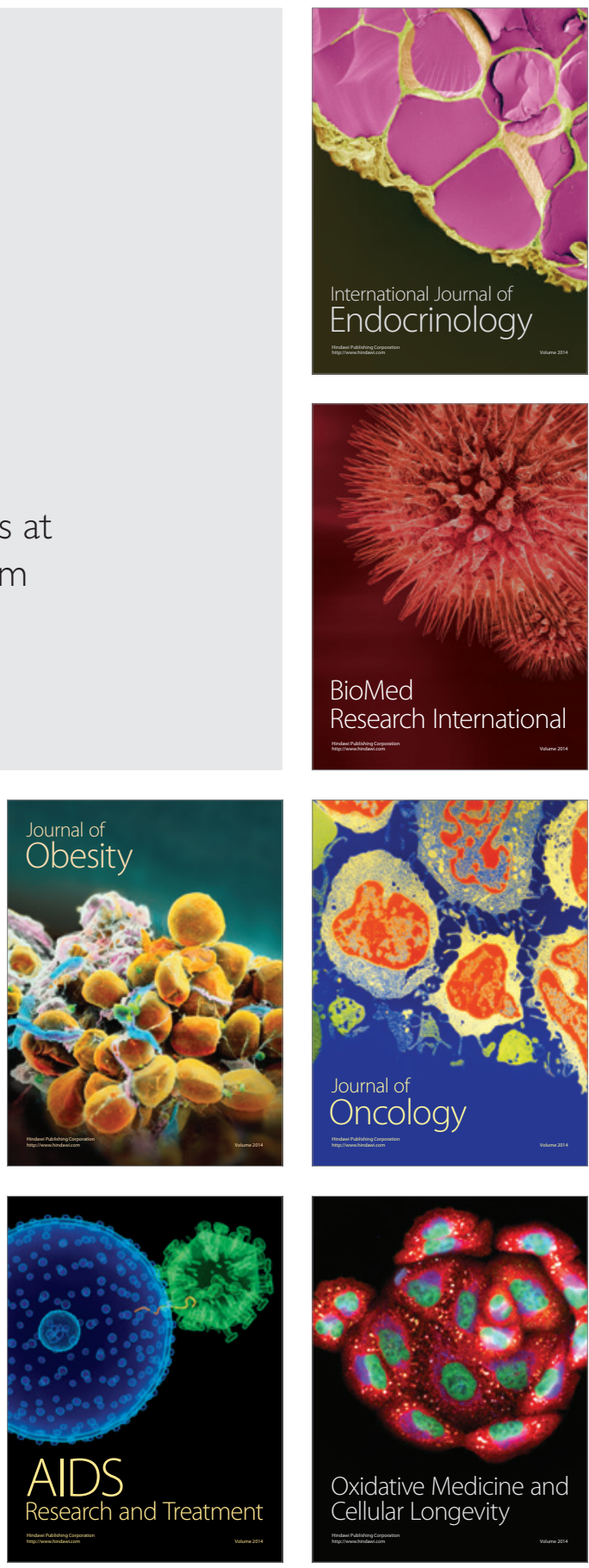